WIENER SLAVISTISCHES JAHRBUCH, Band 57/2011, 101-122

(C) 2011 by Österreichische Akademie der Wissenschaften, Wien

AMIR KaPETANOVIĆ

\title{
Altkroatisch in Versen
}

1. Einführung: Zu Entstehung, Umfang, Klassifikation und allgemeinen EigenSCHAFTEN DES KORPUS VERSIFIZIERTER ALTKROATISCHER TEXTE

Die in altkroatischer Sprache ${ }^{1}$ versifizierte Dichtung, deren schriftliche Spuren von der Mitte des 14. (1368) bis ungefähr zur Mitte des 16. Jahrhunderts reichen ${ }^{2}$, ist ein wichtiger Bestandteil der kroatischen mittelalterlichen Literatur. Es wurde ihr aber in der kroatischen Philologie und der Slavistik bisher ${ }^{3}$ weniger Aufmerksamkeit geschenkt, als sie verdienen würde: Zwar wurden einzelne Gedichte untersucht und mit ihren Varianten veröffentlicht und auch einzelne Gedichtsammlungen publiziert, aber im neuesten umfangreichen dem Mittelalter gewidmeten Panorama wird sie leider gänzlich marginalisiert. ${ }^{4}$ Außerdem lebt bis heute noch der alte Irrtum fort, dass alle altkroatischen Texte in Lateinschrift geschrieben seien und alles glagolitisch und kyrillisch Geschriebene kirchenslavisch sei. Dieser Irrtum führte zur Vorstellung, dass die altkroatische Sprache zwar sporadisch in versifizierten mittelalterlichen kirchenslavischen Texten zum Vorschein komme, aber es nur wenige altkroatische Gedichte gebe, weil es ja auch nur sehr wenige versifizierte mittelalterliche Texte in Lateinschrift gibt. In Wahrheit war die mittelalterliche Dichtung der kroatischen ethnischen Gemeinschaft größtenteils altkroatisch, nämlich čakavisch, ${ }^{5}$ und

${ }^{1}$ Als altkroatisch bezeichnen wir alle kroatischen Volksidiome, die in geschriebenen Texten vom Ende des 11. bis zum Ende des 15. Jahrhunderts aufscheinen. Der vorliegende Aufsatz behandelt nicht die liturgischen Gedichte in kirchenslavischer Literatursprache kroatischer Redaktion.

2 Die obere Grenze ist insofern willkürlich festgesetzt, als man Abschriften mittelalterlicher Texte nur bis zur Mitte des 16. Jahrhunderts berücksichtigt und die neueren beiseite lässt, weil ihre Sprache oft modernisiert ist.

3 Erst 2010 ist die monographische Chrestomatie über die mittelalterliche kroatische Dichtung (HSP 2010) erschienen. Siehe die Rezensionen Fališevac 2010 und Tatarin 2010.

4 Siehe die Rezension des Buchs Malić 2009: Bratulić u. a. 2009.

5 Siehe HSP 2010. 
nicht kirchenslavisch ${ }^{6}$, und altkroatische Verse wurden in allen drei Schriften geschrieben, und zwar vorwiegend in der glagolitischen, weniger in der lateinischen und noch weniger in der kyrillischen. Es stellt sich aber die Frage, ob wir auf der Grundlage der schriftlichen Denkmäler ein wahres Bild von dieser Dichtung bekommen können, weil ja im Mittelalter mehr auswendig gelernt und mündlich überliefert als aufgeschrieben wurde. Und wenn etwas aufgeschrieben wurde, dann häufig aus der Erinnerung heraus, sodass nur ein kleinerer Teil der altkroatischen Dichtung, und zwar vorwiegend religiöse Gedichte, gleich schriftlich verfasst wurde. Auf eine thematisch vielfältige nicht niedergeschriebene mittelalterliche Dichtung weist etwa das 17. Kapitel in J. Šižgorićs De situ Illyricae et civitate Sibenici (1487) hin, in dem heute unbekannte volkstümliche Klage-, Hochzeits-, Liebes-, Arbeits-, Hirten-, Koleda- und Tanzlieder erwähnt werden. Abgesehen von einigen zufällig auf uns gekommenen älteren schriftlichen Zeugnissen volkstümlicher kroatischer Dichtung (wie $O$ jelo, vita jelo, pođ sama na vodu; Još pojdoh ravnim poljem; Ora vija se nad gradom Smederevom) sind die uns vorliegenden nicht vor dem 16. Jahrhundert entstanden.

Die auf Altkroatisch verfasste mittelalterliche Dichtung ist vorwiegend religiös und lässt sich in sieben Gattungen einteilen: 1) Weihnachts gedichte (Proslavimo Otca Boga, Bog se rodi v Vitliomi, Va se vrime godišća, Na kršćenje Gospodnje pesan slavna); 2) Passions - und Ostergedichte (Pisan ot muki Hrstovi, Cantilena pro sabatho, Ja, Marija, glasom zovu, Vidila sam čudo velo, Isusova mučila, Molitvica od križa, Pozdravljenje križa, Raduj se, vsaki verni, Tri Marije hojahu, Uskrse Isus treti dan); 3) Fronle ichnamsgedichte (Zdravo, Božje sveto telo, Zdravo, sveto Božje telo); 4) e s chatolog is che Ge dichte (Pisan na spomenutje smrti oder Plačimo srcem is očima, Sudac gnjevan hoće priti, Bratja, brata sprovodimo, Tu mislimo, bratja, ča smo, Plačnu pesan, bratja, vspojmo, Nu pomisli, o človiče, Bratja, v mladost ne ufajte, Nu poslušaj, Božji puče, Draga bratja i sestrice, Probudi se jure, duše, Tuženje duše i tila, Plačnu pesan sada pojmo); 5) H e il i g e ng e d i c h t e Pisan svetogo Jurja, Mihaile preblaženi, Molitva sv. Margariti); 6) J e s u s- und Marien-Gedichte (Zač mi tužiš, duše, Marijina pisan, Šibenska molitva, Raduj se, o Marije, Rojstvo Marije Divi Danu se vsi ponizimo, Spasi kraljice milosrdna, Spasi, Marije, svojih vernih, Marija, mati cartana); 7) V ol k s s e g n u n e n (Benedictio super populum oder Blagoslov pu$k a$ ). Hinzu kommen noch einige bekannte weltliche Gedichte, satirische, misogyne, reflexive, aber auch die bugarštice (Ora vija se nad gradom Smederevom, Svit se konča, Još pojdoh ravnim poljem, Čuj se vsaki moćno žene, Cesar, kralji, hercegove, $A$ ti, divojko šegljiva). Dann gibt es noch die drei unvollständigen zwölfsilbigen Verse in der Dubrovačka carinska knjiga (zwischen 1421 und 1430), doch lässt sich die Thematik des Werk, aus dem sie stammen, nicht genau bestimmen. Als religiöse

\footnotetext{
${ }^{6}$ Siehe HSP 2010.
} 
mittelalterliche Werke sind noch die in sieben Versionen bekannte Marienklage (Marijin plač) und mittelalterliche Dramen bzw. Mysterien- (Passions- und Oster-) Spiele zu nennen (Muka Isuhrstova oder Muka Spasitelja našega, Uskrsnutje Isusovo, Mišterij vele lip i slavan od Isusa; heilig: Muka svete Margarite); Weihnachtsmysterienspiele sind uns aus Quellen bis zum 17. Jahrhundert nicht überliefert. ${ }^{7}$ Viele der genannten Texte sind uns in einigen Varianten bzw. Versionen bekannt, was für mittelalterliche Texte charakteristisch ist.

Der achtsilbige Vers ist für die kroatische mittelalterliche Dichtung prototypisch. Zwar ist die Frage seines Ursprungs noch immer offen, man rechnet aber mit einem großen Einfluss der lateinischen Kirchenhymnodie auf die nichtliturgische, volkstümliche religiöse Dichtung des kroatischen Mittelalters, ohne auszuschließen, dass auch die damalige mündliche Dichtung an der Entwicklung der kroatischen Versifikation beteiligt war. ${ }^{8}$ Vor der Entstehung der ältesten Spuren der syllabischen Versifikation in altkroatischer Sprache im 14. Jahrhundert (1368 im Kolophon Misal kneza Novaka; 1380 Pariška pjesmarica), als das kroatische Volk kulturell stärker mit dem kyrillomethodianischen Erbe im Osten als mit dem Westen verbunden war, hat wahrscheinlich auch die byzantinische Dichtung die altkroatische beeinflusst. Darauf weisen in kroatischen liturgischen Büchern (z. B. Hrst vskrse iz mrtvih) erhaltene kirchenslavische Gedichte und Spuren des byzantinischen zwölfsilbigen Verses hin. ${ }^{9}$ In diesem älteren, freilich unbelegten Typ der altkroatischen Dichtung, also vor der Festigung des Achtsilbers, herrschte nach der Meinung vieler der metrisch ungebundene, aber gereimte Vers und davor die rhetorisch-rhythmische poetische Prosa. ${ }^{10}$ Darauf weisen auch zwei Gedichte aus der Pariška pjesmarica (Pisan svetogo Jurja, Zač mi tužiš, duše) hin, die sich durch ihre langen anisometrischen gereimten Verse von den anderen Gedichten dieser Sammlung unterscheiden. Über die Eigenschaften der Dichtung des kroatischen Volkes vor der Mitte des 14. Jahrhunderts lässt sich nur mutmaßen, und zwar auf der Grundlage einiger erhaltener Nachrichten über das Singen von Liedern ${ }^{11}$ und von Spuren uralter slavischer, auch vorchristlicher Dichtung. ${ }^{12}$

Da in der kroatischen Dichtung des Mittelalters das Verhältnis zwischen Vers und Prosa noch nicht normiert war, hat man es mit mehreren Übergangsformen zu

${ }^{7}$ Die Texte der angeführten Gedichte, Marienklagen und Mysterienspiele sind mit ihrer philologischen und bibliographischen Beschreibung in HSP: 2010 veröffentlicht.

8 Darüber s. Slamnig 1960: 15; Hercigonja 1975: 174.

9 Einige Forscher erkennen im Text Povaljski prag den byzantinischen zwölfsilbigen Vers, s. Kolendić 1924: 3-6; Kolumbić 1994: 9-23.

10 Hercigonja 1975: 173.

11 Z. B. das Singen von Liedern in ,slavischer Sprache“" in Zadar 1177 anlässlich des Besuchs Papst Alexanders III., das Singen von Liedern in Dubrovnik im 13. Jahrhundert anlässlich des Weihnachts- und Neujahrsfests sowie auch einige kleinere sichere frühe Nachrichten (s. Bujas 1960: 512).

12 S. Katičić 2008. 
tun. E. R. Curtis unterscheidet Kunstprosa (dictamen prosaicum), „einfache Prosa“ (sermo simplex), gereimte Prosa, gemischte Prosa, metrische Poesie und rhythmische Poesie. ${ }^{13}$ Lateinische versifizierte Werke konnten in kroatische Prosa übersetzt (z. B. das Gedicht Ave, maris stella im Vatikanski hrvatski molitvenik), Heiligenlegenden in Prosa im Kroatischen versifiziert ${ }^{14}$ (z. B. Muka svete Margarite) und in ein und demselben Text Vers und Prosa kombiniert werden (z. B. Uskrsnutje Isusovo). Von der Šibenska molitva, einem der ältesten schriftlich fixierten altkroatischen Gedichte, behaupten manche Forscher, sie sei „im Wortgruppenvers“ geschrieben, womit sie den syntagmatischen und an der Rede orientierten Vers ${ }^{15}$ in die Diskussion einbringen. Andere betonen, es handle sich um eine Kombination aus Vers und Prosa $^{16}$, und bezeichnen diese als rezitative Gedichtsprosa ${ }^{17}$. Bisweilen wird gar nicht auf den Gegensatz Vers : Prosa Bezug genommen, sondern spricht man von einem „lyrischen Gedicht“, einem „marianischen Gedicht oder einer Lauda“, von einer „appellativen Lyrik“, einem „religiös-reflexiven Gedicht“ oder vom „Gipfel des gehobenen, hohen Stils im Korpus der versifizierten kroatischen Werke““ ${ }^{18} \mathrm{Im}$ ersten Teil der Šibenska molitva, der an die italienische Lauda erinnert, finden sich anisometrische Verse mit Endreimen, während es sich beim zweiten Teil sicherlich um Gedichtsprosa handelt.

Die mittelalterliche Literatur widersetzt sich auch der Einteilung in lyrische, epische und dramatische Werke; sie bricht mit der antiken Tradition, und ebenso wenig gibt es zwischen den Formen und Gattungen des Mittelalters und der heutigen Literatur eine Kontinuität $t^{19}$. Die neuere Mediävistik untersucht die mittelalterliche Literatur sui generis; wo es keine im Voraus normierten Gattungen gibt, muss ihre Untersuchung von den einzelnen Texten ausgehen, freilich immer in Verbindung mit der ganzen Tradition oder dem regulativen System einer Reihe von Texten. ${ }^{20}$ Eine klare Grenzziehung zwischen lyrischen, epischen und dramatischen Werken ist bei den mittelalterlichen versifizierten Texten schon deshalb nicht möglich, weil die an und für sich dramatischen Mysterienspiele genetisch mit den lyrisch-narrativen geistlichen Gedichten verbunden sind, insbesondere mit denen mit Passionsthematik. Schriftlich überlieferte Epik gibt es gar keine, das Bestehen einer alten kroatischen Epik kann nur aufgrund einzelner Elemente epischer Erzählweise und narrativer Gestaltung in einigen Gedichten (z. B. Pisan svetogo Jurja) erahnt werden.

13 Curtius 1971: 159.

4 Štefanić 1969: 487.

5 Slamnig 1981: 7, 24.

6 Vončina 1975: 20.

7 Z. B. Hercigonja 1975: 177.

Vgl. Fališevac 2007: 16, 18, 20. Kursiv A. K.

19 S. Jauß 1970: 352 und Z. Skrebs kroatische Übersetzung aufgrund des handschriftlichen deutschen Textes.

20 S. Jauß 1970: 338-339. 


\section{2. ÜBERLEGUNGEN ZU DEN WICHTIGSTEN STRUKTURELLEN EIGENSCHAFTEN}

2.1. Die meisten altkroatischen Gedichte sind čakavisch, einige aber, und zwar hauptsächlich jüngere Abschriften älterer čakavischer Gedichte, wurden, soviel wir wissen, in štokavischer Umgebung ${ }^{21}$ adaptiert. Drei marianische Gedichte weisen eine bedeutende kirchenslavische Komponente auf $(35,36,38)$, und in einem sind kajkavische und slowenische Einflüsse zu erkennen (40). Im Folgenden wird vom čakavischen ${ }^{22}$ Altkroatischen die Rede sein, freilich mit einigen Hinweisen auf čakavisch-kirchenslavische und štokavische Gedichte bzw. Gedichtvarianten.

Das Čakavische hat sich am Ende des 11. und am Anfang des 12. Jahrhunderts an der östlichen Adriaküste auf der Grundlage der urkroatischen Dialektgruppe herausgebildet. Im 12. und im 13. Jahrhundert unterlag es vielen phonologischen, morphonologischen und morphologischen Innovationen, wobei sich aber die čakavische Sprachstruktur bis zur Entstehung der ersten Handschriften altkroatischer Dichtung im 14. Jahrhundert ziemlich stabilisiert hat. Die heutige čakavische Mundart besteht aus sechs Dialekten ${ }^{23}$ und nimmt einen kleineren Raum ein als im Mittelalter vor den Migrationen; es wurde auf den nördlich von Korčula und Lastovo gelegenen Inseln und im Norden des Festlandes bis Istrien und bis zur slowenischen und kajkavischen Grenze gesprochen, und im Osten und Südosten, etwa an der Linie Una - Dinara - Cetina - westlicher Pelješac, grenzte das Čakavische an die westštokavischen Dialekte. ${ }^{24}$ Wegen der Langgestrecktheit seines Areals hat es sich schon im 13. und 14. Jahrhundert in eine nördliche und eine südliche Zone, wenn auch nur geringfügig, zu differenzieren begonnen. Das dialektal inhomogene Gebiet von Zadar (dort trafen die beiden čakavischen Dialekte, Ikavisch-Ekavisch und Ikavisch, aufeinander), spielte als Kulturzentrum eine wichtige Rolle; von dort aus breiteten sich literarische Texte in beide Richtungen entlang der Adriaküste aus. Die ältesten (štokavischen) Zwölfsilber aus Dubrovnik (Sada sam ostavljen ...) weisen den jekavischen und ikavischen Reflex des Jats auf, haben keinen Synkretismus der Pluralkasus, verwenden den Adriatismus daž (anstelle von $d a z ̌ d$ ) und erhalten die Sequenz -jdim Präsensstamm des präfigierten Verbs iti. In jüngeren Abschriften aus Dubrovnik

${ }^{21}$ Solche sind: Sudac gnjevan hoće priti, Tu mislimo, bratja, ča smo, Probudi se jure, duše, Zač mi tužiš, duše. Siehe HSP 2010: 137-141 und 159-160, 175-177 und 189-190, 227231, 263-265 und 268-269. Als štokavisch können auch das Fragment des Zwölfsilbers Sada sam ostavljen und die bugarštica Ora vija se nad gradom Smederevom angesehen werden, s. HSP 2010: 330-331, 334-336.

22 Cal Cakavisch ist hier als diatopische Stilisierung der kroatischen Literatursprache gemeint.

${ }^{23}$ Nach Dalibor Brozovićs Klassifikation hat jede der drei kroatischen Mundarten sechs Dialekte. In der jüngsten Darstellung der čakavischen Mundart (Lisac 2009) heißen deren Dialekte Buzetisch, südwestliches Istrisch, Nordčakavisch, Mittelčakavisch, Südčakavisch, Lastovisch (auf der Insel Lastovo). Zur in der kroatischen Dialektologie allgemein anerkannten terminologischen Unterscheidung zwischen Mundart (narječje = Gruppe von Dialekten), Dialekt (dijalekt), Ortssprache (mjesni govor) und Gruppe von Ortssprachen (grupa govora) s. Brozović 1963-64 und Moguš 1977.

24 Nach Lisac 1996: 15. 
und štokavischen Adaptationen älterer čakavischer Gedichte sind markante čakavische Merkmale beseitigt (Jekavisierung, što statt $\check{c} a, k o j i$ statt $k i$, Lok. Sg. m. $-u$ statt $-i$ u. a.).

Morphologische Paläoslovenismen (-go etwa in togo 16d:160a $\mathrm{a}^{25}$, sego 19a:196b, -ši etwa in mučiši 49e:56b, -t etwa in pojut 20a:197a, položet 20a:198a, selten z. B. der Komparativ N. Sg. fem. većši 5:195b) tauchen in altkroatischen Versen nur gelegentlich und nur aus stilistischen Gründen, etwa um die kroatischen Formen zu variieren, auf. Als lexikalische Kirchenslavismen sind z. B. nińa, vinu, akosi, vaspet zu erwähnen.

\subsection{Phonologie}

2.2.1. Das čakavische phonologische System des 14. und 15. Jahrhunderts hatte fünf Vokale (/a/, /e/, /i/, /o/, /u/), dazu noch das (manchmal als /ar/ und seltener als /er/ realisierte ${ }^{26}$ ) silbische / $/ \mathrm{r} /$ und das silbische $/ 1 /$ (das manchmal und ab dem 15. Jahrhundert immer öfter als $/ \mathrm{u} /$ erscheint). In einigen jüngeren Texten wie z. B. in den meisten Varianten der Marienklage (Marijin plač) und in den Mysterienspielen steht /u/ für das silbische /1/, manchmal findet man Dubletten wie z. B. slnce/sunce (36: 63b). Der glagolitische Vrbnički plač hat /al/ (stalp 49c:5b) neben /u/ (puk 49c:5a), was eine nur lokale Erscheinung ist (auf der Insel Krk koexistieren die beiden Varianten noch heute). Wenn žav 'žao' (52:94a) kein Schreibfehler und keine absichtliche Synärese ist, könnte es auf einen nordčakavischen Wandel $-l>-u>-v$ hinweisen. In älteren Gedichten aus dem Süden ist das silbische /1/ $(12,37 \mathrm{a})$ noch gut erhalten, aber in einigen jüngeren ist es zu /u/ gewandelt ( $\check{z} u c ̌$ 49g:95b). Wenn wir die Konventionen der Schreibung des Halbvokals zum Abzug bringen, beweisen alle erhaltenen Gedichte direkt oder indirekt, dass er in starker Position zu /a/ geworden war (vodac 4:132a). Die čakavische starke Realisierung des an und für sich schwachen Halbvokals in erster Wortsilbe (zali 22a:74a) führt dazu, dass in manchen Texten drei Varianten aufscheinen, z. B. mani/meni/mni (49a:108b;112a;118a) und auch kadi/kade < kъdě (3a:168a, 3b:235b), das als nordčakavisches Charakteristikum dem südčakavischen $g d i$ gegenübersteht. Allerdings kommen in einigen alten Texten aus

${ }^{25}$ Vor dem Doppelpunkt steht jeweils die Nummer des Texts, ein Buchstabe bestimmt gegebenenfalls die betreffende Textvariante oder -version. Nach dem Doppelpunkt ist die Zahl des Blattes angeführt, wonach a die recto- und b die verso-Seite bezeichnet bzw. mit a, b, $\mathrm{c}$ oder $\mathrm{d}$ die Spalte angegeben ist. Wenn auf mehrere Stellen desselben Textes verwiesen wird, dann sind die betreffenden Ziffern und Buchstaben durch das Semikolon getrennt. Die Angaben von Belegen sind in keiner Weise vollständig, sondern dienen nur als Illustration.

${ }^{26}$ Seltener erscheinen in den Texten zwei Reflexe (parsi/prvo 49c:4a;5b) und noch seltener drei (smrti/berže/barzo 46:71a), die im heutigen Cakavischen niemals gemeinsam auftreten. Allerdings verzeichnet A. Sojat (1981: 239) aus Cres sporadische Varianten wie z. B. hrvatski, hervatski, harvatski, und die Restituierung des kurzen silbischen /r/ erklärt er durch den Einfluss von Adstraten und der Standardsprache. Der angeführte Beleg stammt aus dem glagolitischen Text und gibt zu erkennen, dass der Text von einer lateinschriftlichen Vorlage abgeschrieben wurde. 
dem Norden sowohl gdi als auch kadi vor (49a:105a;124a, 7:26b;26a), etwa je nach metrischem Erfordernis. Gdi ist im Süden häufiger als kadi, erscheint aber auch in einigen Versionen der Marienklage und in den Mysterienspielen, die im Norden geschrieben wurden, trotzdem heißt es im Nordwesten kadi Sin Božji ležaše (3d:38b) und im Süden gdi Sin Božji ležaše (3e:7b). Dem čakavischen Reflex des /ę/ nach j, ž und $\check{c}$, also /a/ (prijal 5:195a, žajna 46:70a, poča 13:22b), steht vereinzelt auch /e/ gegenüber (jezik 49g:97b, žejan 42:198b, poče 49a:120a); die Auswahl hängt mitunter vom Reim ab (z. B. jeti x propeti, jati x povidati 50c:16b;32b).

Was das Jat betrifft, so sind in den Gedichten alle seine Reflexe belegt, so wie ja auch heute noch in den čakavischen Dialekten (ikavisch, ikavisch-ekavisch, ekavisch, auf Lastovo jekavisch). In den meisten Texten gibt es sowohl den ikavischen als auch den ekavischen Reflex, aber in unterschiedlichem Verhältnis: In manchen dominiert der ikavische, in anderen der ekavische; man kann darin ein Ikavisch-Ekavisch sehen, in dem allerdings von den Regeln Meyers und Jakubinskis zu Gunsten entweder des ikavischen (17b, 18b, 18c) oder des ekavischen Reflexes abgewichen wird (3b, 7, 12, 4). Selten verhalten sich die grammatischen Morpheme ikavischekavisch (33b), was darauf hindeuten könnte, dass die Niederschrift in ekavischer Umgebung erfolgte. In einigen Texten sind Belege überhaupt selten (jeweils ein ekavischer und ein ikavischer in $17 \mathrm{a})$, oder es liegen nur wenige ikavische vor $(8,13)$ oder ikavische mit wenigen ekavischen in lexikalischen Morphemen (17d, 37a, 3f, 39, 46) oder Dubletten wie z. B. tilo/telo (16). Es gibt auch ekavisierte Abschriften von wahrscheinlich ikavischen Vorlagen (28). Den ikavischen Reflex gibt es in den meisten Gedichten der in Split oder seiner Umgebung ${ }^{27}$ entstandenen Pariška pjesmarica fast gar nicht (lipotu, svita, priobraženje 32a:199b), allerdings tritt auch der ekavische nur selten auf (većati 29, und hauptsächlich das Präfix pre- und die Präposition pred). Reime wie slavimo x věmo, sěděti x biti $(30 \mathrm{a})^{28}$ und die Schreibung

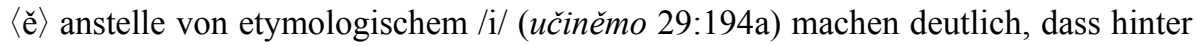
der Schreibung $\langle\check{\mathrm{e}}\rangle$ der ikavische Reflex, ein wichtiges Merkmal des Südčakavischen, steht und dass $\langle\check{\mathrm{e}}\rangle$ nur ausnahmsweise für /e/ geschrieben wird (ojmě 29:

27 Malić 1972: 31.

${ }^{28}$ In kroatischen Texten aus der zweiten Hälfte des 14. bis zur Mitte des 16. Jahrhunderts erscheint manchmal auch das Graphem $\langle\check{e}\rangle$, steht aber für kein besonderes Phonem, sondern für einen seiner Reflexe. Zu der Zeit war das Phonem /ě/ sicherlich schon dephonologisiert und die Schreibung $\langle\check{\mathrm{e}}\rangle$ nur noch eine Konvention. Darauf weist nicht nur die Tatsache hin, dass in der ältesten glagolitisch geschriebenen kroatischen mittelalterlichen Dichtung manchmal auch etymologische /i/ und /e/ mit $\langle\check{e}\rangle$ notiert werden, sondern auch, dass sich in keinem mittelalterlichen kroatischen Text in Lateinschrift ein graphischer Hinweis auf ein Phonem /ě/ finden lässt. Aus orthographischen Eigenheiten glagolitischer Gedichte darf nicht auf ein Fortbestehen des Jat-Phonems oder den Einfluss des phonologischen Systems der kirchenslavischen Literatursprache auf die altkroatische Literatur vom Ende des 14. und vom 15. Jahrhundert geschlossen werden (war es doch vielmehr umgekehrt: Kroatische Idiome beeinflussten das phonologische System der kirchenslavischen Literatursprache kroatischer Redaktion). 
194a). In den jüngeren Texten des Gebiets um Šibenik (18a, 34) ist vorwiegend das Ikavische mit einigen Ekavismen vertreten, in den anderen Texten gibt es noch weniger ekavische Belege (3de, 6a, 18e, 31, 49dg). All das zeigt, dass in den čakavischen literarischen Texten hinsichtlich der Reflexe des Jats eine große Vielfalt verschiedener Übergänge und Kombinationen herrschte.

2.2.2. Die Sprache der čakavischen altkroatischen Gedichte hat 23 Konsonanten (/b/, $/ \mathrm{c} /, / \mathrm{c} /, / \mathrm{c} /, / \mathrm{d} /, / \mathrm{f} /, / \mathrm{g} /, / \mathrm{h} /, / \mathrm{j} /, / \mathrm{k} /, / / \mathrm{l} /, / \mathrm{l} /, / \mathrm{m} /, / \mathrm{n} /, / \mathrm{n} /, / \mathrm{p} /, / \mathrm{r} /, / \mathrm{s} /, / \breve{\mathbf{s}} /, / \mathrm{t} /, / \mathrm{v} /, / \mathrm{z} /, / \check{\mathrm{z}} /)^{29}$. Im Gegensatz zum damaligen Štokavischen, zu den wenigen štokavischen Varianten altkroatischer Gedichte und zur heutigen kroatischen Standardsprache fehlen die Phoneme / $/ \bar{z}$ / und /z//. Das Phonem /f/ ist mit Lehnwörtern (farizej neben pervar < februarius) ins frühe Altkroatische übernommen worden und durch Lautwandel wie z. B. $p ъ v>f$ (vgl. ufanje) auch in Erbwörtern entstanden.

Einige urslavische Laute und Lautsequenzen werden genauso wie in den heutigen čakavischen Dialekten realisiert: */t'/ > /ć/ (pića 34:127a), */d'/ > /j/ (rojen 29:194a $)^{30}$; so auch das /g/ in Lehnwörtern wie z. B. angel $>$ anjel. Beachte auch */st'/ und */sk'/ > /šć/ (klišće 49a:124a, išće 50b:131b) und */zd'/ (und */zg'/) > /žj/ (dažjilo 46:69b) sowie /čr/ (črvi 20a:197b).

In den älteren Gedichten bleibt silbenschließendes /1/ erhalten (gospodoval 49a: 109a, dilnik 9:83a), in den jüngeren čakavischen Texten gibt es hingegen Belege für den štokavischen Wandel $-l>-o$ (uzvisio 53a:4a, vidio 52:84b) und, seltener, für den Ausfall des /1/ (umar', prije' 52:85a;91a). Manchmal geht /h/ verloren (selten ćer 29: 194a, öfter oću 30a:198b). Gewöhnlich ist der Rhotazismus /ž/ > /r/ (moreš 33a: 195b, ar 33a:195b, jure 36:63b). Sporadisch tritt der Wandel $-m>-n$ zu Tage (ovin glasom 49a:105b), und zwar nicht nur in čakavischen, sondern auch in štokavischen Lokalsprachen der Küstenregion. Manchmal fehlen die Resultate der II. Palatalisierung (D Sg. majki/majci 52:83b, mnogimi/mnozim 39:24b) oder der sekundären Jotierung (zledju, karvju, smartju, veselje, zgovorenje 49a:107a; 107b; 119a; 124a; 123a). Unverändert bleiben /jt/ im Infinitiv und /jd/ im Präsensstamm des präfigierten Verbs iti (ojti, dojde 49a:105a;119b), sporadisch wird $/ \mathrm{kl} /$ anstatt $/ \mathrm{kl} /$ realisiert (prokļati 18b:127a). Gewöhnlich ist die Assimilation an der Wortgrenze des Typs $\check{s}$ ńih, z Bogom (24a:77b, 22a:74a); die ältesten Gedichte wie z. B. die in der Pariška pjesmarica zeigen sie auch dort, wo nach glagolitischem Usus das Zeichen ' für den

29 Auf Grund der Handschriften kann man nicht sagen, ob in einigen damaligen čakavischen Lokalsprachen dieses Lautinventar größer oder kleiner war und ob die distinktiven Merkmale dieser Laute mit denen in der kroatischen Standardsprache übereinstimmten.

${ }^{30} \mathrm{Im}$ ganzen Korpus gibt es nur ein Beispiel, in dem $\langle\mathrm{dj}\rangle$ an der Morphemgrenze geschrieben wird (sladji 2c:28b), was ein früher Beleg einer solchen etymologischen Schreibung ist, wie sie auch bei neuzeitlichen čakavischen Schriftstellern vorkommt. Ausgesprochen wurde wohl slaji, wie die gleiche Stelle in zwei älteren Varianten zeigt. Mit einem štokavischen Einfluss auf das Gedicht ist nicht zu rechnen $(\langle\mathrm{dj}\rangle=/ \xi /)$, und die primäre Jotation hatte schon längst gewirkt. 
Halbvokal geschrieben wird (z. B. $\check{s}^{\prime}$ nim $^{\prime}$ 33a:195b). Prothetisches $/ \mathrm{j} /$ vor $/ \mathrm{i} /$ wie $\mathrm{z}$. B. in jime (18e:194b) ist wegen der graphischen Ambivalenz bei $/ \mathrm{i} / \mathrm{und} / \mathrm{j} / \mathrm{nicht}$ in allen Texten gesichert, keinen Zweifel lässt aber eine Schreibung wie z. B. gime zu. In den Texten vom Kvarner und aus Süddalmatien findet man vs- z. B. in vsi, vsaki (37a:38b, 8:83a), erst im 16. Jahrhundert manifestiert sich die Metathese (z. B. svi/vsimi 52:82a;85a). Im ältesten Werk, der Pariška pjesmarica, gibt es keine Metathese in vs- (vsi, vsak 20a:197a;197b), wohl aber, und zwar reichlich, in jüngeren Texten aus dem Süden (svi 49g:71a). Sehr selten sind unzweifelhafte Belege für den Wandel / $/ \mathrm{l} />/ \mathrm{j} /$ (trubja 18a:78b). Die Dissimilation $z n$ - > zl- (zlamen 10:157a) ist im Korpus dieser Gedichte nicht ungewöhnlich (znamenaše 29:194b neben zlamenje 51:12a), hingegen ist die Dissimilation $m n->v n$ - (vnogo 50c:15b) auch in jüngeren Texten sehr selten. Das Nebeneinander von $i z(-), z(-)$ und manchmal auch is- findet man sowohl im čakavischen Norden als auch im Süden, und zwar auch in ein und demselben Text (z. B. isprosimo, iz ogńa / z praha 18c:102a). Die Präposition und das Präfix $v(-)<v b(-)$ ist in nordčakavischen mittelalterlichen Texten ziemlich gut erhalten (23b), auch vor zwei Konsonanten wie z. B. in vstati (18g:164a), es erscheint in altkroatischen Versen dieses Gebiets aber auch $u$, was heute für das südöstliche Čakavisch charakteristisch ist; im Norden wurde die mit $u$ entstandene zusätzliche Silbe einst auch zu metrischen Zwecken genutzt, sodass ein Text Dubletten wie z. B. v tvoji uši / u nebeska vrata (19b:131a), v mladost / u jakost (25c:65a) aufweisen kann. ${ }^{31}$ In den ältesten Texten aus dem Südosten steht $v(-)$ neben $u$ ( $v$ muke, vstane, aber $u$ kih, ukripil 18a:78b) und auch neben va(-) mit Vokalisierung des Halbvokals in erster Wortsilbe.

2.2.3. Für die meisten čakavischen altkroatischen Verse ist das Drei-Akzente-System $^{32}$ anzunehmen, auch wenn sich darüber aus der Schreibung nichts erschließen lässt.

\subsection{Morphologie}

Die altkroatischen Verse von der Mitte des 14. bis zum Anfang des 16. Jahrhunderts spiegeln das geneuerte morphologische System der späten altkroatischen Sprache čakavischen Typs wider, in dem deklinierbare Wörter drei Genera, drei Numeri und sieben Kasus und konjugierbare drei Genera, drei Numeri und drei Personen unterscheiden. Die Substantive haben die drei heutigen Deklinationen: die a-Deklination (maskuline und neutrale Substantive und unbestimmte Adjektive), die e-Deklination (feminine Substantive und unbestimmte Adjektive) und die i-Deklination (maskuline und feminine Substantive). Die ersten zwei Deklinationen unterscheiden ein Paradigma palataler und ein Paradigma nichtpalataler Wortstämme. Dualformen

\footnotetext{
${ }^{31}$ Diese Dubletten können nur in glagolitischen Texten zuverlässig festgestellt werden, weil in der lateinischen Schrift $\langle\mathbf{v}\rangle$ und $\langle\mathbf{u}\rangle$ ambivalent waren.

32 Lukežić 1999: 131.
} 
sind in den Denkmälern aus der zweiten Hälfte des 15. und dem Anfang des 16. Jahrhunderts seltener (oči moji 8:82b, tvoji uši 19a:196b; naju 29:194b, budevě 29: $194 \mathrm{~b}$, jesta 50c:8b, pojdosta 52:94a).

\subsubsection{Substantivische Deklination}

2.3.1.1. Im N Sg. haben die maskulinen Formen der Substantive und der unbestimmten Adjektive die Endung - $\varnothing$, die neutralen -o/-e und die femininen - $a$ (e-Deklination) oder - $\varnothing$ (i-Deklination). Belegt sind auch männliche Namen, die im NV Sg. auf -o (Janko), -e (Ive, Šime) und -a (Ana, Baraba, Ijuda/Juda, Ilija, Jeorjija, Jezva, Kajfa, Satana, Toma $)^{33}$ enden. Namen wie z. B. Janko deklinieren nach der a-Deklination und hypokoristische Kurznamen wie z. B. Ive wie auch die weiblichen Namen Mare und Magde nach der e-Deklination. Nach der e-Deklination werden auch männliche Namen wie z. B. Toma dekliniert. Der i-Deklination gehören außer femininen Substantiven auch einige maskuline an (z. B. put, ljudi). Im N Pl. sind die Endungen gewöhnlich $-i(\mathrm{~m}),$.$-a (n.), -e$ oder $-i$ (f.). Auf $-e$ enden z. B. krstjane (8:83a) und Židove (49g:90b) u. dgl., aber auch grobove (49a:119b), popove (49f:49b). Doch schon in den ältesten Gedichten sind in ein und demselben Text Dubletten möglich (popove neben remetani 42:198a-198b). Die Osorsko-hvarska pjesmarica (ca. 1530) enthält ein satirisches Gedicht mit einer Aufreihung von N Pl.-Formen auf $-i$ und -(ov)-e: Cesar, kralge, hercegove, / duž, baruni $i$ knezove / $i$ svi zemlom ki vladaju / male vire skazan daju (47:155a).

2.3.1.2. Der G Sg. der Substantive endet auf $-a$ (m. und n.), $-e /-i$ (f.) oder $-i$ (i-Deklination) und der unbestimmten Adjektive auf $-a$ (m. und n.) und $-e$ (f.). Bei $-e /-i$ handelt es sich um den früheren Gegensatz zwischen dem $-i(<-y)$ der nichtpalatalen Stämme und dem $-e(<-e)$ der palatalen, der in den ältesten kroatischen Gedichten noch belegt ist, allerdings mit Schwankungen (z. B. ribe neben istini 42), wobei aber das -e klar überwiegt, auch in den nördlich von Zadar, wo der alte Gegensatz in einzelnen Ortschaften bis heute erhalten ist, entstandenen Gedichten (djavle sile, večne rane 19b:131a). Ansonsten wurde der alte Gegensatz in fast allen kroatischen Dialekten wie in der Standardsprache aufgehoben. ${ }^{34} \mathrm{Im}$ G Pl. ist in allen drei Genera die gewöhnliche Endung - (učenik 50b:140b, rebar 15a:23b, tug 8:82b), außer in der iDeklination, wo $-i$, $-i h$ und $-i j u$ nebeneinander existieren. Seltener belegt sind $-o v$ (grihov 33c:27b), -ev (Žudijev 49c:24a) und -i (miseci 49a:111b). Die substantivierten Adjektive haben -ih aus der adjektivisch-pronominalen Deklination (mrtvih 8: 83b, ekavisch-čakavisch: mrtveh 18i:182a, štokavisch-jekavisch: -ijeh, z. B. zlijeh $18 \mathrm{~g}: 244 \mathrm{a})$.

33 S. Brozović Rončević - Kapetanović 2009.

${ }^{34}$ Lukežić - Turk 1998: 146, 149. 
2.3.1.3. Der D Sg. m. und n. endet auf $-u$, der D Sg. f. auf $-i$. In den glagolitischen Texten wird bei nichtpalatalem Stamm die Endung $-i(<-\check{e})$ nach der Konvention manchmal mit $\langle\check{e}\rangle$ geschrieben, dahinter kann sich aber im größeren, dem ikavischen und ikavisch-ekavischen, Teil des čakavischen Gebiets nur der ikavische Reflex oder (überwiegend) die Endung - $i$ der palatalen Deklination verbergen. Die Substantive der i-Deklination enden auf $-i$. Die bestimmten Adjektive haben im Femininum sowohl die ältere Endung - $i$ (Šimunovi 50c:11b) als auch die neuere, aus der adjektivisch-pronominalen Deklination übernommene Endung -oj. Der D Pl. m. und n. hat -om/-em (D Pl. stražnikom 52:95a, kraļem 3a:168a) und der D Pl. f. -am (tugam 49b: 138b); selten und wahrscheinlich aus metrischen Gründen wird ein - $e$ hinzugefügt (Židovome, mišćanome 49g:80b). Die Substantive der i-Deklination enden auf -em (ludem 49e:61b).

2.3.1.4. Die Endungen des A Sg. m. und n. stimmen so wie in der kroatischen Standardsprache bei Unbelebten mit denen des Nominativs überein und bei Belebten mit denen des Genitivs. Die Feminina haben $-u$ (e-Deklination) oder - $\varnothing$ (i-Deklination). Anstelle der älteren Endung $-i$ im A Pl. m. und f. steht manchmal die neuere Endung -e (grěhi, kńigi, molbe moje 18b:126b-127a). Auch in der Pariška pjesmarica findet man neben der älteren Endung im A Pl. m. die neuere, die mit der Zeit im Südosten die Oberhand gewonnen hat (glase dobre, za grěhe 2a:196b).

2.3.1.5. Im V Sg. m. steht wie in der kroatischen Standardsprache -e bei nichtpalatalen und $-u$ bei palatalen Stämmen; in Substantiven wie Janko ist der V Sg. gleich dem N Sg. wie im Neutrum. Das Femininum hat in der e-Deklination drei Endungen: am häufigsten $-o$, aber auch -e (Substantive auf -ica) und $-a$ (V Sg. = N Sg.). In der i-Deklination ist die Endung $-i$. Relikte älterer Vokativformen sind $\operatorname{sinu}(2 \mathrm{~b}$ : 148b/149a); sine ist nur in einigen neueren Texten häufig (z. B. 50c:72b). Bei den Feminina überwiegt die alte Endung -e der palatalen Stämme in duše (vgl. Zač mi tužiš, duše), ${ }^{35}$ Gospoje, Marije (49a:103b; 49b:136a). Im V Pl. sind die Formen gleich wie die im N Pl.

2.3.1.6. Besonders markant in der ältesten čakavischen Dichtung ist die noch heute im nördlichen Čakavischen vorhandene Endung $-i$ im L Sg. der maskulinen und neutralen Substantive (v pakli 17d:160b, v sirotstvi 39:24a). Seltener ist -e, vgl. z. B. na dreve (7:26a), worin zwar das Formans -es- der s-Deklination abhanden gekommen, die nicht auf Jat zurückgehende Endung $-e$ jedoch erhalten ist. ${ }^{36}$ Aber auch die neuere Endung $-u$ tritt auf (na oltaru 10:156b), und zwar - neben älterem $-i(<-\check{e} /-i)$ - schon in der Pariška pjesmarica (světu, dolu 32a:199a), wobei auch neuere Denkmäler das ältere - $i$ (ogńi 18e:194b) aufweisen. Die e- und die i-Deklination haben - $i$.

${ }^{35}$ Z. B. findet man die Dubletten duše/dušo in neueren Handschriften wie z. B. in der Muka aus dem Jahr 1556: Sada, zala dušo grišna : To si, duše, razumila (50c:9a).

$36 \mathrm{Im}$ Korpus gibt es mehrere Belege der Form drivi (50c:16b, 49a:112b). 
Die unbestimmten femininen Adjektive können im L Sg. wie im D Sg. sowohl die ältere als auch die neuere Endung -i/-oj aufweisen. Im L Pl. haben die Maskulina und Neutra meist -ih (dilih 52:89b), selten -eh (jasalceh 2a:196b) oder -oh (nadroh 2a:196b) und die Feminina der e-Deklination -ah (mukah 49c:3b), die i-Deklination -eh (žalosteh 49e:54b), selten -ih (častih 47:155a).

2.3.1.7. Im I Sg. haben maskuline und neutrale Substantive die Endungen -om(e) und -em(e) (stolom 50c:56b, dvorome 49g:78b, mečem 50b:136a; mlikom 49e:53a, simkome 49g:92a, veseljem 34:127a). Bei den Feminina der e- und der i-Deklination lässt sich die Entwicklung von -oju (děvoju 5:195B) zu -ov (Martov 49b:144b) verfolgen; daneben gibt es - $u$ (ženu 50c:22b) und das neue -om(e) (družbom 49:137a, zorome 49g:78b), das wir oft in Texten südlicherer čakavischer Provenienz finden, wo es allmählich die Oberhand gewonnen hat. In manchen altkroatischen Versen treten verschiedene Endungen des Instrumentals gleichzeitig auf, z. B. s sestrom Martov nas utiši; svoju smrtju iskupiti (49b:144b). Feminine Substantive der i-Deklination haben die Endungen -ju (zledju 49a:107a), -jom (ričjom 52:93b) oder -ev (pltev 34:127b). Für das nördliche Čakavisch ist die Endung -u (Devu 3a:168a, družbu 25b:79b) typisch, $-o^{37}$ ist nicht belegt. Seltener ist -ov (pravdov 17c:133b) ${ }^{38}$, kommt aber in Texten im weiteren Umkreis des mittelčakavischen Gebiets vor. Im Plural haben maskuline und neutrale Substantive die Endung -i (lupeži 49a:110a), feminine -ami (suzami 52:88b); die i-Deklination weist -mi auf (pohotmi 26:151a, ļudmi 50c:7b). Im Dual sind einige Namen für Körperteile mit der Endung -ima belegt (parsima 50c:19b, očima 17c:133a), in neueren Texten treten sie auch mit der Endung -ami auf (rukami 49f:63b).

\subsubsection{Adjektivisch-pronominale und besondere Deklinationen}

In der adjektivisch-pronominalen Deklination stimmen die Endungen im Großen und Ganzen mit denen der kroatischen Standardsprache überein, außer dass im DLI Pl. die Kasusendungen nicht zusammengefallen (D Pl. -im [-em, -ijem], L Pl. -ih [-eh, -ijeh], I Sg. -imi [-emi, -ijemi]) und die Dualendungen erhalten sind (z. B. L Du. dvoju 50b:120a, D Du. mojima 50c:72b, I Du. slznima 40:239a). Im I Sg., GDLI $\mathrm{Pl}$., DI Du. ist bei nichtpalatalen Stämmen in den wenigen čakavischen Texten aus dem Norden der ekavische Reflex des Jats zu erwarten (z. B. vseh 6b:229b, slavnemi 6b:229b) und in den seltenen Abschriften aus Dubrovnik der jekavische Reflex (z. B. tvojijeh 32b:152a, svojijemi 32b:151b). Im D Sg. m. und n. ist $-u$ erhalten, im L Sg. gibt es keinen vokalischen Auslaut, und dem I Sg. wird in jüngeren Texten, aber selten, - $e$ hinzugefügt (ńome 49g:99b). Im DL Sg. f. tritt bei palatalen Stämmen die alte Endung -ej neben der neueren Endung -oj auf (L Sg. tvojej 33c:81a, D Sg. tvojoj 49e:70a, L Sg. vražjej 51:8a); im I Sg. f. trifft man auf -eju (svojeju 6b:228b),

${ }^{37} \mathrm{Zu}$ den Endungen $-u$ und - $o$ siehe z. B. Lukežić 1998: 129-132.

38 Zu dieser Endung s. Ivšić 1939: 247-248, 250; Malić 2002: 199-200. 
-u (moju 29:194b, Svetu 3a:168a), selten -ov (kov 2b:148b/149a) und -ovje (onovje, blaženo[v]je 34:127b). Belegt sind auch der archaische G Sg. f. ńeje (21a:70a), oft auch in possessivischer Funktion, und ne (anstelle des nicht belegten Possessivpronomens njezin). Manchmal erscheint im A Pl. m. und f. die alte Form der 3. Person des Personalpronomens je (18bc:102a). Das čakavische Pronomen ki, ka, ko wechselt sich in neueren Texten manchmal mit koji, koja, koje ab. Der Genitiv des Interrogativpronomens $\check{c} a$ lautet česa $(50 \mathrm{c}: 5 \mathrm{~b})$.

Zum alten und nordčakavischen I Sg. f. - $u$ oder $-o v$ (tobu 18d:1d, tobov 18b: 127a) ist anzumerken, dass das Gedicht Tu mislimo, bratja, ča smo in der Pariška pjesmarica (entstanden wahrscheinlich im čakavischen Süden) tobu und sobu (20a: 197b) hat, während in den nördlichen, jüngeren Niederschriften dieses Gedichts (20bc) an der betreffenden Stelle neueres tobom, s sobom (20b:131b) steht. Belegt ist auch die alte Form mnoju (50b:156a). Korrekt verwendet sind die Dualformen GD naju (29:194b).

\subsubsection{Verbalformen}

In der 1. Sg. Präsens erscheint hauptsächlich die ältere Endung - $u$ (zovu 7:26a, pravlu 2a:196b), in den jüngeren Texten ist aber auch bei thematischen Verben $-m$ belegt (ostavlam 49a:117a), wobei in ein und demselben Text Dubletten auftreten (plaču, ne zgorim 18e:194b). Es gibt zahlreiche Belege für Aorist- und Imperfektformen. Hervorzuheben sind die älteren Imperfektformen auf -homo (držahomo 51:6a) in der 1. Pl. und -hote (zovihote 24c:26a) in der 2. Pl. Das Perfekt wird mit den betonten und den unbetonten Formen des Perfekts des Hilfsverbs biti gebildet und tritt sowohl vor als auch nach dem Hauptverb auf (ki te je toliko polubil 32a:199b, koj' vas karvju jest iskupil / i sebi vas jest zaručil 49g:70b, spomenuli jesmo mi se 52: 94a). In den älteren Texten kann das Futurum vollendeter Verben durch die Präsensformen ausgedrückt werden (on te ļubi i posluša 33a:195b), aber auch mit Hilfe des Hilfsverbs $h(o)$ téti + Infinitiv (se hote otvoriti 18g:164a, 3. Pl. te priletiti 24b:25a) oder mit den Präsensformen des vollendeten Hilfsverbs biti + Infinitiv (budu ustati 18a:78b). In der 3. Sg. des Imperativs tritt sowohl die mit der 2. Sg. übereinstimmende Endung auf (slava budi 2b:148b/149a) als auch die Konstruktion neka +3 . Präsens (neka plače ma sidina 50c:79b). Außer dem einfachen ist oft auch der zusammengesetzte Imperativ belegt (ne htij plakat 52:83b). Sporadisch wird der typisch čakavische Konditional (bim nigovala 49a:122b) neben gewöhnlichem bih ... + Partizip gebraucht. In aus dem Gebiet nördlich von Zadar stammenden Texten finden wir manchmal mit kajkavischen Präsensformen wie z. B. bum, buš, bu gebildete Futura, so in der Muka aus dem Jahre 1556 (bum viditi, buš govoriti, bu visiti 50c: $35 \mathrm{a}$ ). Es sind auch die älteren Partizip-Formen nicht ungewöhnlich (vide, reki $17 \mathrm{c}$ : 133b, videće 20a:197a, ostavivše 42:198a), aber auch die jüngeren sind belegt (iznemagajući 32a:199a, umuknuvši 53a:82a). 


\subsection{Syntax}

Bislang gibt es keine detaillierten Untersuchungen zur Syntax in der älteren kroatischen Dichtung. Obwohl die Metrik die syntaktischen Verhältnisse beeinflussen kann - man denke z. B. an die Einschränkungen, denen in den Achtsilbern der Gebrauch von Wörtern, Syntagmen und Sätzen unterliegt, die auch durch den Reim und durch bestimmte Stilfiguren bedingt sein können, vgl. etwa die Wortfolge im Vers ne ukrede da vam ga tko (52:95a), oder an die ungewöhnliche Einbettung von Gliedsätzen (Neka prija ja to vidim, / je li umarl, i izvidim 52:84b, Jesi li sam totu bio / kad je umarl, $i$ vidio? 52:84b) -, stehen grundsätzlich alle syntaktischen Merkmale der älteren kroatischen Dichtung im Einklang mit dem čakavischen Sprachsystem und den Gewohnheiten der Dichtung jener Zeit. Manches ist aber für Gedichte charakteristischer als für die Prosa, z. B. wenn in einem Achtsilber zur Steigerung der Prägnanz der Aussage Partizipien an die Stelle zweier Relativsätze treten: deruć lica, skubuć vlasi (52:91b). In den Achtsilbern gibt es häufig auch asyndetische Satzverbindungen und Parataxen; dass es sich dabei um ein poetisches Stilmittel und nicht etwa um eine Unterentwickeltheit der damaligen kroatischen Sprache handelt, zeigen die damaligen Prosatexte, die mehr zu syndetischen Verknüpfungen und Hypotaxen neigen.

Die Enklitika sind in den Gedichten, aber auch in den damaligen Prosatexten sowie in den Renaissancegedichten ${ }^{39}$ nicht immer nach der heute gültigen Regel gereiht: wohl in poslat ću ga do Iruda (50c:52a), nich aber in: nego ga će nihdar ojti (49g:72b), da ga ću poslat Isusa jati (50c:32b), ali barž se ga vi bojite (50c:43b), zato ju ću pomazati (52:92b), ka se će zda dokončati (50b:137b). Ein negiertes verbales Prädikat verlangt nicht unbedingt den Genitiv des Objekts wie in älteren, insbesondere in unter kirchenslavischem Einfluss stehenden Texten (tužnih dušic ne ostavi 50c:39a, ali: ne znaš muku ka te čeka 50c:8b, da tolik strah ne imamo 49g:88b). Die doppelte Verneinung ist obligatorisch, und ne steht immer vor dem Verb (on da ništar ne tuguje 50c:41b, ni nijedan na 'vom sviti 50c:56b, ne bi nigdir pomoćnika 52:83b), im Unterschied zu den kirchenslavischen Texten, in denen es auch anders zu finden ist. Manchmal steht in Gedichten ne nicht beim Hilfsverb, sondern beim Hauptverb: da bi nigdar ne rodilo (50c:60b), da bi puku pak ne rekli (52:94b), a ja li ću ne plakati (52:87a), aber nicht immer: Gospodine, to nećemo učiniti (29:194a-194b), ja ne bim se razlučila (49b:135a), da ju ne bum ja viditi (50c:16a).

Auffällig sind anstelle von Akkusativformen verwendete Genitivformen von Substantiven für Unbelebtes: kad vam dojdu grad podsisti (49g:88b), aber: pogledajmo Božja grada (2a:196b), ti si nebo otvorila (33b:81a), aber: Ti si nebes otvorila (33a:195b). Der Genitiv steht manchmal ohne die Präposition ot/od beim Kompara-

39 Zum Beispiel im Gedicht Jur nijedna na svit vila von H. Lucić: Parsti joj su pravni, prosti ... (Lucić 1968: 42). 
tiv: Mladinac je slaji meda (2a:148b/149a), aber tvarja ti sam već od driva (49a: 116a). Nicht ungewöhnlich ist in mittelalterlichen kroatischen Gedichten der periphrastische Komparativ mit veće $(+\mathrm{G})+$ Positiv (Lice veće slnca světlo 5:195a, veće bolězniva mati 5:195b), der von veće + Positiv + nego + Positiv (veće martvu nere živu 6a:91b) unterschieden werden muss. Ein Besitzverhältnis konnte auf verschiedene Weisen ausgedrückt werden, nämlich wie heute mit Hilfe von Possessivpronomina (moj, tvoj...), Possessivadjektiven (da budeš Božja nevista 31:6b) und Genitivattributen (ki se pravi sin višńega Boga 50c:54b), aber es war damals auch die Verbindung ot/od + G (Sin od Boga ki se diše 52:82b) nicht ungewöhnlich. Das Possessivpronomen njezin ist nicht belegt, an seiner Stelle steht der Genitiv Singular des Personalpronomens für die 3. Person (jeje tugu š ńom tužite 49a:103a, sinka ńeje osujena 49f:50b, pozri majke $i$ ńe slze 49b:141b). Im Maskulinum und Neutrum wird sowohl das Possessivpronomen als auch der Genitiv des Personalpronomens verwendet: tu vidimo ńegovo tilo (20c:72a), život ńegov ako ļubiš (49c:5a); ko vidimo ńega tilo (20b:131a), i ńega zapovid on razbijaše (49b:143b). Anstelle von $o+$ Lokativ finden wir nach romanischem Vorbild ot/od + Genitiv (... pisan ot svetogo Jeorjije konnika 29:193b, ča ću sad reć od Marije 49g:97b). Die Präposition za mit dem Genitiv bringt wie in der mittelalterlichen Prosa ein Eingreifen in das im Genitiv genannte Objekt zum Ausdruck ${ }^{40}$ (za mrtvih se pomolimo 18d:1d). Bei der Präposition blizu steht sowohl der Genitiv als auch der Dativ (blizu križa one stahu 49a: 115b, blizu križu ona staše 5:195a). Belegt ist die Verwendung des Nominativs anstelle des Vokativs (O Marija, Božja mati 19c:29a, neben: O Marije, Božja mati 19b:131a). Die Präposition po steht nach romanischem Vorbild auch beim Akkusativ, wo heute der Lokativ stünde (zvedoše ga van po vrata 49a:109b). Anstelle des Lokativs erscheint manchmal der Akkusativ (jere ne imam, plačna majka, / veće na svit sinka draga 49g:82a, kako visiš na križ nagi 52:88a). Im Korpus gibt es nach italienischem Vorbild auch einige Beispiele für $z a+$ Infinitiv anstelle eines Finalsatzes: ti pristupiti bliže križu / za biti Gospodina veće blizu (49c:20b), i prolil sam karv svu moju / za učinit volu tvoju (49g:77b). Die Präpositionen $v$ und $s / z$ assimilieren sich oft an ein mit $v$ bzw. $s / z / z$ anlautendes Wort (u grob novi, [v] vartlu momu 52:84a, u grad [s] strahom svi pojdoše 49g:97b, ča Adam sagriši [z] ženu svoju 50c: 22b). Romanischem Vorbild (farelfacere + Infinitiv) sind die Konstruktionen mit učiniti + Infinitiv (... učini se otsuda otd(i) liti 29:194b) und činiti + Akkusativ + Infinitiv nachgebildet ( $t i$ ga čini $k$ sebi priti 20c:73b). Auffällig sind noch Wendungen wie die mit den Aoristformen von jati + Infinitiv (palicami me jaše biti 49a:113b, Šimuna jaše usiliti 49a:113b) und die mit počati/početi + Infinitiv anstelle von Inchoativverben (poča Gospoja tad vapiti 49c:25a).

In der mittelalterlichen kroatischen Dichtung galten dieselben Regeln zur Verbindung und Einbettung von Sätzen wie in der heutigen kroatischen Standardspra-

${ }^{40}$ Hercigonja 1983: 433. 
che. Hier soll es genügen, für jede Art syndetisch koordinierter bzw. subordinierter Sätze jeweils ein Beispiel zu nennen (die zahlreich belegten einfachen und asyndetischen Sätze sind hier beiseite gelassen). Beispiele von Koordination: Duhom S(ve)tim se važgaše / ter se navkup zgovoriše (2b:148b/149a); Ni obuću ni odiću / ni nosimo s sobom piću, / nego d(u)šu grisi slide, / a grišnici to ne v(i)de (22b:62a); Ajmeh, gdi $t^{\prime}$ su sada stanja / ali tvoja sva imanja? (27a:39b). Beispiele von Subordination: Rečenje jest Pilatovo / da daš tělo Isusovo / Osipu, mužu pravadnomu (49e:68b; Prädikatsatz); Nu mislimo ob tom d(a)n(a)s / gdo na križi umrě za n(a)s! (5:194b; Subjektsatz); Věmo da je Božić d(a)n(a)s (1a:196a; Objektsatz); Pitaj ovih ki su čuli / v cri[k]vi moja govorenja (50b:139a; Attributsatz); pojte gdi je ńega mati (6a:91b; Lokalsatz); O pol noći se rodi, nebo i zemly prosvitli, kako o pol dne svitlo bi (3c: 95a; Modalsatz); Dokle imašs telom žitje, / najdi sebi rajsko bitje (17f:63b; Temporalsatz); S(ve)ti nam Petre, pomozi, / jer su grisi v nas mnozi (7:22b; Kausalsatz); Ot vstoka tri kraļi mnogo dni su jezdili da bi Is(us)a viděli (3b:235b; Finalsatz); Tu Židove Isusa maknu tako da se na tla spade (50c:46a; Konsekutivsatz); Život ńegov ako ļubiš, / milost cesara ti pogubiš (49c:5a; Konditionalsatz); neću slišat vaši bozi, / premda $v$ tuzi jesam mnozi (53b; Konzessivsatz).

\section{LeXik Und Phraseologie}

Zwar treten in altkroatischen Gedichten nicht viele Lehnwörter und Fremdwörter auf, dennoch haben frühere Sprachkontakte ihre Spuren auch in ihrer Lexik hinterlassen. Kirchenslavische Lexeme sind meist absichtlich auf literarischem Weg als stilistische Poetismen übernommen worden, z. B. vinu (2b:148b/149a), vrag (18b: $126 \mathrm{~d})$, akosi (20a:197b), naděja (17d:1d), vaspet (51:8a). Zahlreich sind die aufgrund unmittelbarer Berührung mit dem Italienischen eingedrungenen Italianismen, z. B. sudarij (8:82a), baleštar (24a:73b), sulac (25c:64b), biškanat (49g:71a), facolić (50c:66b), pitar (52:88a), piz (52:88a), škala (52:87b). In Dialogen und Dramen sind sie aber häufiger zu finden als in den Gedichten. In einigen Texten treten Italianismen neben den echtkroatischen Synonymen auf (z. B. lancun und vilahan, lanča und sulica, 52:87b; 92a; 83a; 91b). Auch Kontaktsynonymie gibt es, z. B. vesel und kontent in vesel, kontent za vse lludi (50c). Griechischer oder lateinischer Herkunft sind z. B. ajer (49g:97a), anjel (49g:71b), arkanjel (53a:5b), biskup (22b:62b), gardinal (22b:62b), harat (50c:128b), Germanismen sind z. B. cartan, trošt (40), herceg (48), und als Slowenismen könnten z. B. ker, očak (40:238d) und als Bohemismen z. B. šleta (24c:74b) gelten. In einigen nördlich von Zadar entstandenen Texten dürften auch kajkavische Wörter auftreten (z. B. tretič, pokrivača 50c:48b;154a). Wörter štokavischer Herkunft sind, abgesehen von zašto (49g:75b) und što (51:89b), schwerer zu ermitteln als solche kajkavischer Provenienz.

Was die Onomastik angeht, so gibt es in der kroatischen mittelalterlichen Dichtung keine Belege kroatischer Ethnonyme oder Familiennamen. Personennamen, vor 
allem biblische, ferner hypokoristische Kurzformen (Ive, Magde/Mande, Mare/Mara, Šime, Janko) und von Toponymen abgeleitete Ethnika sind allerdings vertreten. Selten sind Namen historischer Personen (knez Brnardin, vojvoda Janko). ${ }^{41}$

Zuletzt sei angemerkt, dass in den ältesten kroatischen Gedichten viele Phraseme belegt sind, die noch heute in Gebrauch stehen, z. B. proliti (čiju) karv 'jemandes Blut vergießen' ( $i$ karv svetu ńega proli 49a:120a) und nositi ļubav 'Liebe erweisen' (Vidite l' ča učinih vam / za 'nu ļubav ku nosim k vam? 50c:22a).

\section{Schlussfolgerung: Die SPRAChliche Grundlage des kroatischen GedichtsStils}

Die Sprache versifizierter altkroatischer Texte von der Mitte des 14. bis zur Mitte des 16. Jahrhunderts ist hauptsächlich čakavischer Provenienz (abgesehen von einigen wenigen štokavischen Gedichten und Adaptationen). Auf dieser sprachlichen Grundlage, auf der das Reiminventar, zahlreiche Versifikationsmuster und wichtige Stilmerkmale entstanden sind, beruht auch die frühneuzeitliche čakavische, štokavische und später auch kajkavische Lyrik M. Marulićs, H. Lucićs, Š. Menčetićs, Dž. Držićs und vieler anderer, etwa im Hinblick auf die Anzahl der Silben oder den Reim. Insbesondere betrifft das z. B. die Hinzufügung von $-e$ am Wortende (I Sg. zorome 49g:78b), die Apokope (sama s' ti ... 503a:1b), die Synkope (stan'te 50a: $60 \mathrm{~b}$ ) und die Aphärese ( $z a$ 'no mliko 50c:18b), das Nebeneinander kontrahierter und nicht kontrahierter Formen (ma : moja 27:40b, vgl. Zato, sestro, ma Gospoje 49e: $60 \mathrm{~b}$ vs. Tužna moja lakomosti 50a:148b), das Schwanken zwischen auslautendem -l und -o (Jesi li sam totu bio / kad je umarl, $i$ vidio? 52:84b), die Unterschiede in nicht deklinierbaren Wörtern (sad : sada 49a:113b;114b), in verschiedenen Deklinationsendungen (I Sg. - ov, $-u,-o m$ ), die Verwendung de Akkusativs anstelle des Lokativs (na svit 3c:95b) u. ä. In dieser Dichtersprache treten viele rhetorische und stilistische Figuren auf wie z. B. Interjektionen in verschiedenen Varianten (jao / ajme / ajmeh / ojme / ojmeh 52), die Onomatopöie (daske tutńu, zvoni mlče 6a:91b), das Paregmenon (plačem plači sarce tvoje 50c:61b), die Epizeuxis (ja te molim, prosti, prosti 52:87a), das Hyperbaton (da bi mogal poznat koga 49g:74a), die Anapher (Gospoje ... Gospoje 34:127a), die Personifikation (Za tu ima pojti Ufanje v sukńi žuti noseć sunce od harte ... 50c:128b), die Metapher (Gospoje, ti si blaženih div i mučenic kruna $i$ vse urešenje 34:127a), die Metonymie (v svitlo ruho obuci se / $i$ ne skubi tvojih vlasi 51:20b) usw. sowie zahlreiche konzeptuelle konventionelle Metaphern (z. B. Liebe als Feuer): toko ļubvom važgan biše (31:6b).

Die Sprache der altkroatischen (hauptsächlich čakavischen) Gedichte war stilistisch und versifikatorisch flexibel, stellte aber strukturell eine stabile Dichtersprache dar, die einen Zeitraum von zwei Jahrhunderten und ein langgestrecktes Gebiet an der vorwiegend čakavischen östlichen Adriaküste umspannte.

${ }^{41}$ Darüber detaillierter Brozović Rončević - Kapetanović 2009. 
Quel1en

1. Proslavimo Otca Boga - A: Pariška pjesmarica, 1380, Französische Nationalbibliothek, Paris, Code slave 11, 195b-196a; B: Berčićev zbornik br. 5, Ende des 15. Jh., Russische Nationalbibliothek, Sankt Petersburg, Bč 5, 28a$28 \mathrm{~b}$

2. Bog se rodi v Vitliomi - A: Pariška pjesmarica, 1380, Französische Nationalbibliothek, Paris, Code slave 11, 196a-196b; B: Zbornik duhovnoga štiva, Ende des 15. Jh., Archiv HAZU, Zagreb, IV a 92, 148b/149a; C: Berčićev zbornik br. 5, Ende des 15. Jh., Russische Nationalbibliothek, Sankt Petersburg, Bč 5, 28b-29a

3. Va se vrime godišća - A: Ljubljanski (beramski) brevijar, 14./15. Jh., National- und Universitätsbibliothek, Ljubljana, Ms 161, 168a; B: Petrisov zbornik, 1468, National- und Universitätsbibliothek, Zagreb, R 4001, 235b236a; C: Picićeva pjemarica, 1471, Bodleian Library, Oxford, MS Canon. Ital 193, 95a-96b; D: Korčulanski latinični zbornik, 15. Jh., Österreichische Nationalbibliothek, Wien, sign. 1354, 38a-38b; E: Osorsko-hvarska pjesmarica, um 1530, Archiv HAZU, Zagreb, I a 62, 7a-8a; F: Knjige Disipula (B), 1558, Archiv HAZU, Zagreb, VIII 126, $240 \mathrm{c}$

4. Na kršćenje Gospodnje pesan slavna - Zbornik duhovnoga štiva, Ende des 15. Jh., Archiv HAZU, Zagreb, IV a 92, 132a-132b

5. Pisan ot muki Hrstovi - Pariška pjesmarica, 1380, Französische Nationalbibliothek, Paris, Code slave 11, 194b-195b

6. Cantilena pro sabatho (Jegda čusmo željne glasi) - A: Mađarski latinični kodeks 540/1, 14. Jh., Ungarische Nationalbibliothek, Budapest, Cod. Lat. 540/1, 91b; B: Petrisov zbornik, 1468, National- und Universitätsbibliothek, Zagreb, R 4001, 228b-229b

7. Ja, Marija, glasom zovu - Berčićev zbornik br. 5, Ende des 15. Jh., Russische Nationalbibliothek, Sankt Petersburg, Bč 5, 26a-27a

8. Vidila sam čudo velo - Klimantovićev zbornik I, 1501-1512, Franziskanerkloster auf dem Ksaver, Zagreb, 81b-83b

9. Isusova mučila - Osorsko-hvarska pjesmarica, um 1530, Archiv HAZU, Zagreb, I a 62, $54 \mathrm{~b}-56 \mathrm{~b}$

10. Molitvica od križa - Osorsko-hvarska pjesmarica, um 1530, Archiv HAZU, Zagreb, I a $62,155 \mathrm{~b}-157 \mathrm{a}$

11. Pozdravljenje križa - Osorsko-hvarska pjesmarica, um 1530, Archiv HAZU, Zagreb, I a $62,157 \mathrm{a}-158 \mathrm{a}$

12. Raduj se, vsaki verni - Tkonski zbornik, erstes Viertel des 16. Jh., Archiv HAZU, Zagreb, I a $120,21 b-22 a$

13. Tri Marije hojahu - Tkonski zbornik, erstes Viertel des 16. Jh., Archiv HAZU, Zagreb, I a $120,22 \mathrm{a}-23 \mathrm{a}$.

14. Uskrse Isus treti dan - Tkonski zbornik, erstes Viertel des 16. Jh., Archiv HAZU, Zagreb, I a $120,23 \mathrm{a}-23 \mathrm{~b}$

15. Zdravo, Božje sveto telo - A: Tkonski zbornik, erstes Viertel des 16. Jh., Archiv HAZU, Zagreb, I a 120, 23b-24a; B: Knjige Disipula (B), 1558, Archiv HAZU, Zagreb, VIII 126, 239b

16. Zdravo, sveto Božje telo - Klimantovićev zbornik I, 1501-1512, Franziskanerkloster auf dem Ksaver, Zagreb, 81a-81b

17. Pisan na spomenutje smrti (Plačimo srcem i s očima) - A: Misal kneza Novaka, 1368, Österreichische Nationalbibliothek, Wien, Code slav. 8, 269b; B: Picićeva pjesmarica, 1471, Bodleian Library, Oxford, MS Canon. Ital 193, 100a-101a; C: Zbornik duhovnoga štiva, Ende des 15. Jh., Archiv HAZU, Zagreb, IV a 92, 133a-133b; D: Oxfordski zbornik, 1486, Oxford, Ms. Canon. Lit. 412, 160a; E: Klimantovićev zbornik I, 1501-1512, Franziskanerkloster auf dem Ksaver, Zagreb, 76a-77a; F: 
Klimantovićev zbornik II, 1514, Russische Nationalbibliothek, Sankt Petersburg, Bč 1, 63a-63b

18. Sudac gnjevan hoće priti - A: Šibenski franjevački latinični zbornik br. 20, Anfang 15. Jh., Kloster des Heiligen Franziskus, Šibenik, rkp. br. 20, 78b; B: Berlinski misal B. Krbavca, Staatsbibliothek, Berlin, Ms. Ham. 444, 126cd; C: Picićeva pjesmarica, 1471, Bodleian Library, Oxford, MS Canon. Ital 193, 101a-102a; D: Misal kneza Novaka, 1368. (geschrieben 1486), Österreichische Nationalbibliothek, Wien, Cod. slav. 8, 1cd; E: Lekcionar Bernardina Splićanina, gedruckt in Venedig 1495, 194b; F: Dubrovački (dominikanski) lekcionar, Anfang 16. Jh. (Dominikanski samostan, Dubrovnik, Handschrift Nr. 39, 143a-144a; G: Klimantovićev zbornik I, 1501-1512, Franziskanerkloster auf dem Ksaver, Zagreb, 164a-165a; H: Akademijin fragment (IV a 80/33), Archiv HAZU, Zagreb, IV a 80/33, nicht paginiert; I: Beramski brevijar, 15. Jh. (geschrieben 1559), National- und Universitätsbibliothek, Ljubljana, Ms 161, 182ab

19. Bratja, brata sprovodimo - A: Pariška pjesmarica, 1380, Französische Nationalbibliothek, Paris, Code slave 11, 196b-197a; B: Zbornik duhovnoga štiva, 15. Jh., Archiv HAZU, Zagreb, IV a 92, 131a; C: Berčićev zbornik br. 5, Ende 15. Jh., Russische Nationalbibliothek, Sankt Petersburg, Petrograd, Bč 5, 29a; D: Klimantovićev zbornik I, 1501-1512, Franziskanerkloster auf dem Ksaver, Zagreb, 71a-71b; E: Klimantovićev zbornik II, 1514, Russische Nationalbibliothek, Sankt Petersburg, Bč 1, 61a

20. Tu mislimo, bratja, ča smo - A: Pariška pjesmarica, 1380, Französische Nationalbibliothek, Paris, Code slave 11, 196b-197a; B: Zbornik duhovnoga štiva, 15. Jh., Archiv HAZU, Zagreb, IV a 92, 131a; C: Klimantovićev zbornik I, 1501-1512, Franziskanerkloster auf dem Ksaver, Zagreb, 71a-71b; D: Klimantovićev zbornik II, 1514, Russische Nationalbibliothek, Sankt Petersburg, Bč 1, 61a; E: Libro od mnozijeh razloga, 1520, Archiv HAZU, Zagreb, IV a 24, 128a

21. Plačnu pesan, bratja, vspojmo - A: Klimantovićev zbornik I, 1501-1512, Franziskanerkloster auf dem Ksaver, Zagreb, 70a-71a; B: Klimantovićev zbornik II, 1514, Russische Nationalbibliothek, Sankt Petersburg, Bč 1, 60b$61 \mathrm{a}$

22. Nu pomisli, o človiče - A: Klimantovićev zbornik I, 1501-1512, Franziskanerkloster auf dem Ksaver, Zagreb, 73b-75a; B: Klimantovićev zbornik II, 1514, Russische Nationalbibliothek, Sankt Petersburg, Bč 1, 62a-62b

23. Bratja, v mladost ne ufajte - A: Klimantovićev zbornik I, 1501-1512, Franziskanerkloster auf dem Ksaver, Zagreb, 75a-76a; B: Klimantovićev zbornik II, 1514, Russische Nationalbibliothek, Sankt Petersburg, Bč 1, 62b-63a

24. Nu poslušaj, Božji puče - A: Klimantovićev zbornik I, 1501-1512, Franziskanerkloster auf dem Ksaver, Zagreb, 77a-79a; B: Klimantovićev zbornik III, 1509, Russische Nationalbibliothek, Sankt Petersburg, Bč 2, 25a-26a; C: Klimantovićev zbornik II, 1514, Russische Nationalbibliothek, Sankt Petersburg, Bč 1, 63b-64b

25. Draga bratja i sestrice - A: Klimantovićev zbornik I, 1501-1512, Franziskanerkloster auf dem Ksaver, Zagreb, 79a-80b; B: Klimantovićev zbornik III, 1509, Russische Nationalbibliothek, Sankt Petersburg, Bč 2, 26a-26b; C: Klimantovićev zbornik II, 1514, Russische Nationalbibliothek, Sankt Petersburg, Bč 1, 64b-65a

26. Probudi se jure, duše - Libro od mnozijeh razloga, 1520, Archiv HAZU, Zagreb, IV a 24, $149 \mathrm{a}-151 \mathrm{a}$

27. Tuženje duše i tila - Osorsko-hvarska pjesmarica, um 1530, Archiv HAZU, Zagreb, I a $62,37 \mathrm{~b}-41 \mathrm{~b}$

28. Plačnu pesan sada pojmo - Akademijin fragment (IV a 80/33), Archiv HAZU, Zagreb, IV a $80 / 33$, nicht paginiert 
29. Pisan svetogo Jurja - Pariška pjesmarica, 1380, Französische Nationalbibliothek, Paris, Code slave 11, 193b-194b

30. Mihaile preblaženi - A: Pariška pjesmarica, 1380, Französische Nationalbibliothek, Paris, Code slave 11, 198b-199a; B: Berčićev zbornik br. 5, Ende 15. Jh., Russische Nationalbibliothek, Sankt Petersburg, Bč 5, 27b-28a

31. Molitva svetoj Margariti - Šibenski franjevački latinični zbornik br. 8, Ende des 14. oder Anfang 15. Jh., Kloster des Heiligen Franziskus, Šibenik, Handschrift Nr. 8, nicht paginiert, letzte Seite

32. Zač mi tužiš, duše - A: Pariški pjesmarica, 1380, Französische Nationalbibliothek, Paris, Code slave 11, 199a-199b; B: Libro od mnozijeh razloga, 1520, Archiv HAZU, IV a 24, 151a-152a

33. Marijina pisan - A: Pariška pjesmarica, 1380, Französische Nationalbibliothek, Paris, Code slave 11, 195b; B: Berčićev zbornik br. 5, Ende 15. Jh., Russische Nationalbibliothek, Sankt Petersburg, Bč 5, 27b; C: Klimantovićev zbornik I, 1501- 1512, Franziskanerkloster auf dem Ksaver, Zagreb, 80b-81a

34. Šibenska molitva - Šibenski franjevački latinični zbornik br. 11, um 1380, Kloster des Heiligen Franziskus, Šibenik, rkp. br. 11, 127a-127b

35. Raduj se, o Marije - Glagoljični misal MR 180, Ende 15. Jh., Metropolitana, Zagreb, MR $180,63 \mathrm{~b}$

36. Rojstvo Marije Divi - Glagoljični misal MR 180, Ende 15. Jh., Metropolitana, Zagreb, MR 180, 63b

37. Danu se vsi ponizimo - A: Vinodolski zbornik, 15. Jh., Archiv HAZU, Zagreb, sign. II a 15, 38b; B: Korčulanski latinični zbornik, 15. Jh., Osterreichische Nationalbibliothek, Wien, 1354, 38a; C: Osorsko-hvarska pjesmarica, um 1530, Archiv HAZU, Zagreb, I a 62, 6a-6d

38. Spasi kraljice milosrdna - Brevijar po zakonu Rimskoga dvora, gedruckt in Venedig $1491,377 \mathrm{c}$

39. Spasi, Marije, svojih vernih - Tkonski zbornik, erstes Viertel des 16. Jh., Archiv HAZU, Zagreb, I a 120, 24a-24b

40. Marija, mati cartana - Knjige Disipula (B), 1558, Archiv HAZU, Zagreb, VIII 126, 238d

41. Benedictio super populum (Blagoslov puka) - Abschrift von H. Morović aus der FilippiHandschrift (18. Jh.)

42. Svit se konča - Pariška pjesmarica, 1380, Französische Nationalbibliothek, Paris, Code slave 11, 198a-198b

43. Sada sam ostavljen - Liber statutorum doane, 1277 (Notiz zwischen 1421 und 1430), Staatsarchiv Dubrovnik, Serie XXXV, Dogana, Bd. 1, 34a

44. Još pojdoh ravnim poljem - Band II. von F. Minutius, 1484, Staatsarchiv Zadar, SZN, br. 60, Testamenthülle

45. Ora vija se nad gradom Smederevom - Lo Balzino, Handschrift von Rugerio de Pacienza, 1497, Stadtbibliothek Augusta, Perugia, Antico Fondo, F 27, 70b-71a

46. Čuj se vsaki moćno žene - Tkonski zbornik, erstes Viertel des 16. Jh., Archiv HAZU, Zagreb, I a 120, 68b-71a

47. Cesar, kralje, hercegove - Osorsko-hvarska pjesmarica, um 1530, Archiv HAZU, Zagreb, I a $62,155 \mathrm{a}-155 \mathrm{~b}$

48. A ti, divojko šegljiva - Zadarski rukopis, 17. Jh., Archiv HAZU, Zagreb, I a 44, 81a-81b

49. Marijin plač - A: Picićeva pjesmarica, 1471, Bodleian Library, Oxford, MS Canon. Ital. 193, 103a-127b; B: Zbornik duhovnoga štiva, 15. Jh., Archiv HAZU, Zagreb, IV a 92, 134a-148a; C: Rukopis Vrbničkoga plača, Ende 15. oder Anfang 16. Jh., Archiv HAZU, Zagreb, VII 160, 1a-17b; D: Splitski ulomak plača, Ende 15. oder Anfang 16. Jh., Franziskanerkloster auf Poljud, Split, 1 Blatt; E: Klimantovićev zbornik I, 1501-1512, Franziskanerkloster auf dem Ksaver, Zagreb, 44a-70b; F: Klimantovićev zbornik II, 1514, Russische Nationalbibliothek, Sankt Petersburg, Bč 1, 48b-59b; G: Osorsko-hvarska pjesmarica, um 1530, Archiv HAZU, Zagreb, I a 62, 70a-100a (verschollene Blätter: 66-69, $89,94)$ 
50. Muka Isuhrstova / Muka Spasitelja našega - A: Klimantovićev zbornik II, 1514, Russische Nationalbibliothek, Sankt Petersburg, Bč 1, 59b-60b; B: Tkonski zbornik, erstes Viertel des 16. Jh., Archiv HAZU, Zagreb, IV a 120, 109a-161b; C: Zbornik prikazanja, 1556, Archiv HAZU, Zagreb, IV a $47,3 \mathrm{a}-82 \mathrm{a}$

51. Uskrsnutje Isusovo - Tkonski zbornik, erstes Viertel des 16. Jh., Archiv HAZU, Zagreb, I a $120,1 \mathrm{a}-21 \mathrm{~b}$

52. Mišterij vele lip i slavan od Isusa - Zbornik prikazanja, 1556, Archiv HAZU, Zagreb, IV a $47,82 \mathrm{a}-95 \mathrm{~b}$

53. Muka svete Margarite - A: Firentinski zbornik, 15./16. Jh., Bibliothek Mediceo-Laurenziana, Florenz, Ashb(urnham) 1582, 1a-6b; B: Šibenski rukopis, 16. Jh.; C: Zadarski rukopis, I a 44, Archiv HAZU, Zagreb, I a 44, 1a-28a

\section{Literatur}

Bratulić 2009: Josip Bratulić u. a., Povijest hrvatskoga jezika, 1. knjiga: Srednji viBrozović 1963-64: jek, Zagreb

hrvatskosrpske dijalektologije, osobito u klasifikaciji dijalekata, Jezik 2, Zagreb, 53-60

Brozović Rončević - Kapetanović 2009: Dunja Brozović Rončević - Amir Kapetanović, Onimi u srednjovjekovnom pjesništvu, Folia onomastica Croatica 18, Zagreb, 53-119

Bujas 1960:

Gašpar Bujas, Rezultati u proučavanju dijela stare hrvatske poezije, Radovi Instituta Jugoslavenske akademije znanosti i umjetnosti u Zadru 6-7, Zagreb, 509-537

Curtius 1971:

Ernst Robert Curtius, Evropska književnost i latinsko srednjovjekovlje, s njemačkoga preveo Stjepan Markuš, s izvornikom usporedio i redigirao Tomislav Ladan, Zagreb

Fališevac 2007: $\quad$ Dunja Fališevac, Između molitve i stege. Stari pisci hrvatski i njihove poetike. Drugo, prošireno izdanje, Zagreb

Fališevac 2010: $\quad$ Dunja Fališevac, Temeljno djelo o hrvatskom srednjovjekovnom pjesništvu, Forum LXXXII, br. 4-6, Zagreb, 607-615

Hercigonja 1975: $\quad$ Eduard Hercigonja, Srednjovjekovna književnost (= Povijest hrvatske književnosti 2), Zagreb

Hercigonja 1983: $\quad$ Eduard Hercigonja, Nad iskonom hrvatske knjige, Rasprave o hrvatskoglagoljskom srednjovjekovlju, Zagreb

HSP 2010:

Amir Kapetanović - Dragica Malić - Kristina Štrkalj Despot, Hrvatsko srednjovjekovno pjesništvo: pjesme, plačevi i prikazanja na starohrvatskom jeziku (= Biblioteka Hrvatska jezična riznica. Niz Starohrvatska vrela, knj.1), Zagreb

Ivšić 1939:

Stjepan Ivšić, Nekoliko napomena uz starohrvatski tekst „Žića sv. otaca“, Starine 40, Zagreb, 225-251

Jauss 1970: Hans Robert Jauss, Teorija rodova i književnost srednjega vijeka (= Umjetnost riječi 3), Zagreb, 327-352

Katičić 2008: $\quad$ Radoslav Katičić, Božanski boj: tragovima svetih pjesama naše pretkršćanske starine, Zagreb - Mošćenička Draga

Kolendić 1924: $\quad$ Petar Kolendić, Stihovi na povaljskom natpisu iz XII. veka, Južna Srbija, Skoplje, 3-6

Kolumbić 1994: Nikica Kolumbić, Po običaju začinjavac. Rasprave o hrvatskoj srednjovjekovnoj književnosti, Split

Lisac 1996:

Josip Lisac, Hrvatski dijalekti i jezična povijest, Zagreb

Lisac 2009: Josip Lisac, Hrvatska dijalektologija 2: Čakavsko narječje, Zagreb

Lucić - Hektorović 1968: Hanibal Lucić - Petar Hektorović, Skladanja izvarsnih pisan razlicih - Ribanje i ribarsko prigovaranje i razlike stvari ine. Priredio Marin Franičević, Pet stoljeća hrvatske književnosti, Zagreb 
Lukežić 1998:

Lukežić - Turk 1998:

Lukežić 1999:

Malić 1972:

Malić 2002:

Malić 2009:

Moguš 1977:

Slamnig 1960:

Slamnig 1981:

Šojat 1981:

Štefanić 1969:

Tandarić 1973:

Tatarin 2010:

Vončina 1975:

Iva Lukežić, Govori Klane i Studene, Crikvenica

Iva Lukežić - Marija Turk, Govori otoka Krka, Crikvenica

Iva Lukežić, Razvoj i uspostava hrvatskoga jezika u starijim razdobljima, Fluminensia 1/2, Rijeka, 101-142

Dragica Malić, Jezik najstarije hrvatske pjesmarice (= Znanstvena biblioteka Hrvatskog filološkog društva 1), Zagreb

Dragica Malić, Na izvorima hrvatskoga jezika (= Hrvatska jezična baština 2), Zagreb

Dragica Malić, Hrvatski „,izgubljen u prijevodu“ (ili o tzv. Povijesti hrvatskoga jezika), Književna republika 7-9, Zagreb, 258-313

Milan Moguš, Čakavsko narječje: Fonologija, Zagreb

Ivan Slamnig, Antologija hrvatske poezije od najstarijih zapisa do kraja XIX st., Zagreb

Ivan Slamnig, Hrvatska versifikacija: narav, povijest, veze, Zagreb

Antun Šojat, Cres (OLA 23), in: Fonološki opisi srpskohrvatskih/hrvatskosrpskih, slovenačkih i makedonskih govora obuhvaćenih Opšteslovenskim lingvističkim atlasom, Sarajevo, 235-240

Vjekoslav Štefanić i suradnici B. Grabar, A. Nazor, M. Pantelić (Hrsg.), Hrvatska književnost srednjega vijeka (= Pet stoljeća hrvatske književnosti 1), Zagreb

Josip Tandarić, Jezik sekvencija u hrvatskim glagoljskim misalima, Zagreb (unveröffentlichte Magisterarbeit)

Milovan Tatarin, Poezija života vječnoga, Vijenac 427-429, 15. srpnja 2010, Seite 12

Josip Vončina, Zagonetka „Šibenske molitve“, Croatica 6, Zagreb, 738

A bstract: Old Croatian in Verse. Croatian medieval poetry laid the foundations for further development of Croatian poetry (metric patterns, rhyming "dictionary"). In this article, the author wishes to present the main features of the (Čakavian) Old Croatian language as preserved in medieval verses from the mid- $14^{\text {th }}$ to the mid- $16^{\text {th }}$ century. In the introduction, a short description of the corpus is given (including the scope of the corpus and a classification of the texts) and some problems encountered in researching the oldest Croatian verses are pointed out. Then the most important reflections of structural linguistic features are described (phonological, morphological and syntactic) with notes on vocabulary and phraseology. This analysis shows the flexibility and adaptability of the (Čakavian) Old Croatian poetic language and its fairly stable linguistic structure over two centuries on the eastern Adriatic coast.

K e y w o r d s : verse, Čakavian Old Croatian language, Croatian medieval poetry

Amir Kapetanović

Institut za hrvatski jezik i jezikoslovlje

Ulica Republike Austrije 16,

10000 Zagreb, Kroatien

akapetan@ihjj.hr 